\title{
Effects of search criterion upon unanticipated free recall of categorically related words*
}

\author{
LAWRENCE T. FRASE \\ Bell Laboratories, Murray Hill. New Jersey, 07974 \\ and \\ RICHARD KAMMANN \\ University' of Otago. Otago. New Zealand
}

\begin{abstract}
Ss determined whether words in a list were members of a relatively general or specific category (e.g., foods vs vegetables), and then they were given an unanticipated free recall test. Assumptions were that: (1) evaluating a word against a general criterion (e.g.. food) results in the detection of fewer semantic elements than would evaluating it against a specific criterion (e.g., vegetable). and (2) detecting more semantic elements primes memory. In three studies, free recall scores were highest for the specific search. Instructions to form an image or to think of an association for each word did not improve recall. Telling Ss, just before recall, what categories composed the list increased recall clustering. but not recall.
\end{abstract}

The present studies were suggested by the notion that memory for events is a function of the criteria used to encode those events: consequently, it should be possible to alter Ss' recall for words by altering the criterion they employ while attending to those words. For instance. to verify that a bear is an animal may require detecting fewer and less specific properties (e.g., it eats, breathes, has skin) than to verify that it is a land animal (e.g., it eats, breathes, has skin. and walks on land). Similarly. to verify whether a potato is a food may require detecting fewer properties than to verify that it is a vegetable.

"Depth of processing" (Craik \& Lockhart. 1972) may be an appropriate term for this detection process. since it implies that $\mathrm{S}$ has the option. once he has recognized a word. of testing or elaborating only some of the potential properties that define that word. Searching for specific properties may result in the detection of general features as well as specific properties, especially if memory search is hierarchically organized. Detecting more features could thus provide a richer semantic context and thus aid recall. Specific search criteria might also elicit sense impressions (cf. Wickens, Reutener, \& Eggemeier, 1972) which are more effective aids to recall. The question explored in these studies was whether recall is, in fact, higher as a consequence of evaluating words against a relatively specific criterion.

Experiments I-III demonstrate that specific search does aid recall. Experiment III suggests that these effects are not due to total time. to clustering. or to the availability of category labels at recall: nor are they related to Ss' attempts to form images or associations to each word. Specific properties (e.g.. big/small) were more effective encoding criteria than were category

*A portion of this data was presented at the Annual Meeting of the Psychonomic Society. St. Louis. November 1970. Requests for reprints should be sent to Lawrence T. I rase. Bell Laboratories. Room 11-331. Murray Hill. New Jersey 07974. labels (e.g., animal/plant), although these criteria nominally had the same effect of subdividing list words into two cagetories.

\section{EXPERIMENT I}

Method

\section{Subjects}

Eight high school graduates employed as clerks at Bell Laboratories participated.

\section{Materials}

Two 16-word lists were used: (1) a food list, containing the names of eight fruits and eight vegetables (ORANGES, PEARS, POTATOES. BANANAS. SQUASH, BEANS, TANGERINES. CARROTS. ONIONS. APPLES, MANGO, RADISH, CORN. PINEAPPLE. LETTUCE, PEACH); (2) a name list, containing eight male and eight female names (NANCY, FRED, MARY. MIKE. BILL, CLARA. HENRY. LARRY. MIN. TESSY. NORMA. TED, MARTIN. ARNOLD. ELVIRA, JANE). Each list was typed on a separate sheet of paper. with the names in random order.

\section{Procedure}

Fach $\mathrm{S}$ saw both lists of words. For one list. S was instructed to underline "the names of foods." or "people" (general search). I or the other list. S was to underline "the names of vegetables." or "males" (specific search). Thus. for the specific search. Ss would underline only half of the words. Across Ss, the lists were counterbalanced for position (presented first or second), and whether general or specific search was required.

The time taken to go through each list was tined with a stopwatch, starting with list presentation and ending when S turned over the stimulus list. Inmediately after the second list. S was asked to write as many words as he could remember from both lists.

\section{Results}

Mean recall for general search was $4.50(\mathrm{SD}=1.73)$ : 
for specific search. it was $7.13(\mathrm{SD}=3.02): t(7)=2.12$. $p<.05$. There were no significant differences in time taken for the general search $(\bar{X}=10.13 \mathrm{sec}$; $S D=2.96)$ vs specific search $(\bar{X}=11.50 \mathrm{sec}: \mathrm{SD}=5.56)$. There were no significant differences in recall for the eight target words that were to be underlined in the specific condition $(\overline{\mathrm{X}}=4.13: \mathrm{SD}=2.18)$ as opposed to those eight words which were not to be underlined $(\overline{\mathrm{X}}=3.00$ : $\mathrm{SD}=1.94)$. There was thus a slight tendency to recall more target words.

\section{EXPERIMENT II}

Experiment II was intended to replicate and improve Experiment I. It was administered in the same way as Experiment I, to eight new Ss from the same population. Experiment II differed from Experiment I in that (a) two new lists were used, (b) there were two abstract catch words in each list (making a total of 18 words) to indicate whether $S s$ in the general search might pay less attention (checking off all of the words), and (c) an unfilled interval of $3 \mathrm{~min}$ was introduced between the final list and testing. List 1 included large and small land and water animals: GORILLA. KITTEN, WHALE. MINNOW, MOUSE, GRASSHOPPER, HERRING, ELEPHANT, SARDINE, PORPOISE, LION, BARRACUDA, SPIDER, GOLDFISH. GIRAFFE, SHARK, and two catch words. PROCESS and INSPIRATION. In the general condition, Ss were instructed to underline all of "the animals"; in the specific condition, Ss underlined the "small things," or "large things," or "land animals." or "water animals." i.e., the instruction which nominally subdivided the list into two categories was selected randomly from the set of four possible. List 2 included straight or curved objects or geometric figures (as well as the two catch words): SQUARE, SPIRAL, CUPBOARD, MELON, CIRCLE, ARC, FOOTBALL, TRAPEZOID, HOOP, DRAWER, OCTAGON, TABLE, OVAL, BALLOON, PENTAGON, BRICK. In the general condition, Ss underlined the "visible objects"; in the specific condition, Ss underlined "things with straight sides" or "round sides," or "common objects," or "geometrical figures."

\section{Results}

Mean recall for the general search was 5.38 $(S D=3.08)$; for the specific search, it was 8.00 $(\mathrm{SD}=1.87) ; \mathrm{t}(7)=2.45, \mathrm{p}<.025$. There were no significant differences in time taken for the general search $(\bar{X}=24.57 \mathrm{sec} ; S D=10.72)$ vs the specific search $(\bar{X}=29.29 \mathrm{sec}: \mathrm{SD}=20.41)$-after eliminating the times from one atypical $S$ who took about 2 min to do each list. There were no differences in recall for the eight target words that were to be underlined in the specific search $(\overline{\mathrm{X}}=4.25 ; \mathrm{SD}=1.57)$ as opposed to those eight that were not to be underlined $(\overline{\mathrm{X}}=3.75: \mathrm{SD}=2.05)$. Again. it will be noted that recall of the target words was slightly better than recall of nontarget words. Only one
S erroneously underlined one of the catch words. and this was in the specific search condition. Experiment II thus replicated Experiment I.

\section{EXPERIMENT III}

This study included several refinements of the previous procedure. Each $\mathrm{S}$ categorized every word in only one list (using only one criterion), thus controlling the number of positive responses (target words) in the different search groups. Four different lists were used, and data were gathered on Ss' clustering in free recall. In addition, several different search criteria were used. As in the previous studies, there were general and specific search conditions, but in this study there were two specific search conditions, one in which the criterion was a specific property (big/small) and one in which the criterion was a category label (e.g., animal/plant). A difference in recall between these two specific search groups would indicate the importance of the specificity of the criterion. rather than differentiation among words in the list, i.e., recall effects would not be due solely to the fact that Ss discriminated the words in the list into two categories, but to some degree would be due to the criterion against which each separate word was compared. In our view, a comparative property, such as "bigness," would have to be considered more specific than a category label (e.g., animal). since the judgment of "big" or "small" would have to be made within some categorical context (e.g., the context of animals).

One further reason for Experiment III was that we wanted to eliminate the possibility that specific search instructions merely provided Ss with information about the categorical composition of the list (which might aid guessing in recall), and so half of the Ss were told explicitly what the list categorical composition was immediately before recall.

\section{Method}

\section{Subjects}

One hundred and ninety-two undergraduate psychology students participated.

\section{Materials}

Four lists were used. each of which could nominally be subdivided into four categories. These 18-word lists 116 categorically related words plus two abstract catch words) were intended to represent relatively large or small categories of words. List 1 consisted of big and small living and nonliving things; List 2 consisted only of living things (big and small animals and plants); List 3 consisted only of animals (big and small land animals and water animals): and List 4 consisted of straight-edge and curved geometric forms and common objects. List 1 was: GORILIA, CLOVER. CLIFF. WRISTWATCH. MOLSE, DANDELION, PEBBLE, WHALE, SNOWFLAKE. BOULDER. FIR, MONLMENT. FROG. PENCIL. REDWOOD. TRUCK (plus PROCESS and INSPIRATION as catch words). List 2 Was: WHALE. CEDAR. GRASSHOPPER. CLOVER, REDWOOD, SYCAMORE. VIOLETS, GORILLA, PARSLEY. 
WORM, LION, FROG, FIR, DANDELION, ELEPHANT MOLSE. Lists 3 and 4 were the same as those used in Experiment II.

Design

A 6 by 4 by 2 factorial design was used. with four Ss per cell. The factors were search criterion (explained below), list (1-4), and whether $S$ was informed or not informed about the categorical composition of the list before recall.

The search criterion groups were as follows: General search $(G)$ : S categorized each word as to whether it was a member of one category, as described in the procedure section below. A different criterion was necessary for each list. The criteria used for Lists 1.4. respectively, were "tangible objects," "living things," "animals," and "things which could be seen or visualized." Group $2 P$ : Ss categorized the words into two categories which were specific properties. For Lists 1-3, the criterion was whether a word referred to a "big or a small thing." For List 4 , the criterion was whether a word referred to an object that had "straight sides or curved sides." Group 2C: Same as $2 \mathrm{P}$. except that the criterion was a category label and not a property. For Lists 1.4 , respectively, the criteria were "living and lifeless things." "animals and plants," "land and water animals." and "geometrical figures and common objects." Group 4: Ss categorized the words into four categories. For Lists 1-4. respectively. the criteria were "big and small. living and lifeless things." "big and small animals and plants." "big and small land and water animals," and "straight edged and curved geometrical figures or common objects." Groups $2 \mathrm{P}, 2 \mathrm{C}$. and 4 thus required specific search. Group I: Ss were instructed to visualize each word-to form an image. Group $A$ : Ss were instructed to think of an association for each word.

\section{Procedure}

Lach S saw only one list. Four different randomizations of the words in each list were used. The $S$ was given a written instruction which stated the criterion. After reading the instruction. Ss proceeded to the stimulus list which contained the words and four columns to the right. The Ss were instructed to label the columns with letters (determined by E), abbreviating the criteria. using one to four columns depending upon the criterion. That is, Group $G$ used one column, Groups $2 P$ and $2 C$ used two columns, and Group 4 used four columns. Ss placed check marks in the appropriate columns for each word; e.g., one column would be used if the search was for animals, two columns if the search was for land and water animals, and four columns if the search was for large land. large water, small land. and small water animals. In the imagery and association conditions. Ss placed check marks in one column after they had found an image or association to each word. The Ss were told when to begin checking the words, and they recorded the time when they completed the task from time cards displayed at the front of the room. After this task. Ss engaged in an extraneous sentence judging task for about $15 \mathrm{~min}$. and then they took the unanticipated free recall test. Ss were instrueted to list as many of the words as they could recall. At this time, half of the $S$, were informed about the full content of the word list, e.g.. "It may help you to recall if you know that the words fell into several categories as follows: BIG ANIMAL. SMALL ANIMAL. BIG PLANT. SMALL PLANT. ABSTRACT WORDS."

\section{Results}

Recall. response time, and clustering in free recall are reported in Table 1. Clustering was derived from the order in which Ss listed the words. The measure D (Dalrymple-Alford. 1970) was used, which is the
Table 1

Average Scores on Dependent Measures in Experiment III

\begin{tabular}{cccc} 
Group & $\begin{array}{c}\text { Number } \\
\text { Correct }\end{array}$ & $\begin{array}{c}\text { Time } \\
(\mathrm{Sec})\end{array}$ & $\begin{array}{c}\text { Clustering } \\
\text { (Two-Category) }\end{array}$ \\
\hline $\mathrm{G}$ & 5.78 & 46.41 & .18 \\
$2 \mathrm{P}$ & 8.25 & 58.75 & .05 \\
$2 \mathrm{C}$ & 6.78 & 62.34 & .02 \\
4 & 8.25 & 95.00 & .08 \\
$\mathrm{I}$ & 6.59 & 50.16 & .13 \\
$\mathrm{~A}$ & 5.53 & 74.84 & -.01 \\
\hline
\end{tabular}

Note-SE number correct $=.36, S E$ time $=3.86, S E$ clustering $=.059 ; N=32$ for each group.

difference between chance and observed clustering for a given level of recall. The measure $\mathrm{D}$ can vary from +1 to -1 . Clustering scores reported were based on two categories. Scores based on four categories were also analyzed, but they showed no effects.

In terms of free recall, the criterion groups differed significantly; $F(5 / 144)=10.77, \quad p<.001$. Newman-Keuls tests $($ at $p<.05)$ indicated that Groups $2 \mathrm{P}$ and 4 recalled significantly more than the other groups (and did not differ from each other). Lists 1-4 also differed significantly (means were 5.31, 6.67, 7.90, 7.58 , respectively); $\quad F(3 / 144)=15.30 . \quad p<.001$. Information about the categorical content of the lists had no effect. The mean score for the uninformed group was 6.96: for the informed group, the mean was 6.77 .

Criterion groups also differed in the time taken io perform the search task; $F(5 / 144)=21.62, p<.001$. Groups 4 and A differed significantly from each other and also from all other groups (Neuman-Keuls), and Group 2C took longer than Group G. Lists 1.4 also differed significantly in time $(63.54,61.56,59.38$. 73.85 , respectively); $F(3 / 144)=4.44, p<.01$.

There were no differences between criterion groups in clustering. Ss who had been informed of the list composition before recall showed higher clustering $(\overline{\mathrm{X}}=$ .13) than uninformed Ss $(.03) ; \mathrm{F}(1 / 144)=4.34, \mathrm{p}<.05$. Also, Lists 1.4 exhibited different amounts of clustering $(.02, .04, .14, .04$, respectively $): F(3 / 144)=2.84$, $p<.05$.

\section{DISCUSSION}

Experiment III clarified several issues. First, one can distinguish between nominal and effective list discrimination on the basis of Group 2P and Group 2C recall. If the act of discriminating the words into two categories produced the recall effects, Groups $2 \mathrm{P}$ and $2 \mathrm{C}$ should have performed equally well, yet Group 2P recalled significantly more than Group $2 \mathrm{C}$. It appears. therefore, that recall was altered, not simply because $\mathrm{S}$ analyzed the words into a certain number of categories. but because of the nature of the categories used to process the words. As stated in the introduction to Experiment III. the criteria used by Group $2 \mathrm{P}$ might entail a recognition of the categories used by Group 2C. If so, then Group 2P would. in effect, have detected all 
four categories. In fact, recall level was identical for Group 2P and Group 4, and was significantly higher for them than for all other groups.

Experiment III also provided evidence that group differences in recall cannot be attributed to total categorization time. For instance, although Groups 4 and 2P both averaged 8.25 words recalled. Group 4 took considerably longer to categorize the words. Further evidence against a total time explanation is that Group A. which recalled the least of any group, had longer exposure to the list than the other groups (except Group 4).

Experiment III also provided evidence that group differences were not due to the fact that the search criteria aided guessing by restricting the category from which Ss drew for recall. Telling Ss, immediately before recall, what the categorical composition of the list was had no effect. Recall differences must therefore be due to some input, rather than a retrieval, phenomenon.

It is also clear, from Experiment III, that group differences were unrelated to clustering scores.

In short, the differences induced in recall by different search criteria were not directly attributable to total time, clustering, or to a knowledge of the categorical composition of the list.

We have given one plausible reason for the superior recall of words resulting from specific, as opposed to general, search; namely, specific criteria result in the detection of more semantic (denotative) characteristics. In general, our results suggest that thinking about certain characteristics of an object may entail the detection of other salient characteristics, and that this elaborative process can affect the status of that object in memory.

\section{REFERENCES}

Craik, F. I., \& Lockhart, R. S. Levels of processing: A framework for memory research. Journal of Verbal Learning \& Verbal Behavior, 1972, 11, 671-684.

Dalrymple-Alford, E. C. Measurement of clustering in free recall. Psychological Bulletin, 1970, 74, 32-34.

Wickens, D. D., Reutener, D. B., \& Eggemeier, F. T. Sense impression as an encoding dimension of words. Journal of Experimental Psychology, 1972, 96, 301-306.

(Received for publication May 29, 1973; revision received July 19, 1973.) 